\title{
Mucinous Carcinoma of Gall Bladder - A Rare Case Report
}

\author{
Nanda Patil ${ }^{1}$, Vaidehi Nagar ${ }^{2}$ \\ ${ }^{1}$ Professor, Department of Pathology, Krishna Institute of Medical Sciences, Karad. \\ ${ }^{2}$ Tutor, Department of Pathology, Krishna Institute of Medical Sciences, Karad. \\ Corresponding Author: Vaidehi Nagar
}

\begin{abstract}
Background: Mucinous carcinoma of the gall bladder is a very rare type of gall bladder carcinoma. It is characterized by production of extracellular mucin $>50 \%$ of tumour volume.

Case Report: We report a case of primary mucinous carcinoma of gall bladder in a 60-year-old female patient who was diagnosed clinically as acute cholecystitis. Histopathological examination gave the definitive diagnosis in this case.

Conclusion: Mucinous carcinoma of gall bladder exhibit significant clinicopathological difference from conventional adenocarcinoma of gall bladder and display aggressive clinical behaviour.
\end{abstract}

Keywords: Mucinous Carcinoma, Gall Bladder, Primary

\section{INTRODUCTION}

Mucinous carcinoma of gall bladder is a rare subtype of gall bladder carcinoma which constitutes $2.5 \%$ of carcinomas of gall bladder. The tumour is characterized by extracellular mucin production comprising more than $50 \%$ of tumour ${ }^{1}$. When this mucinous component is more than $90 \%$ of tumour volume, it is called as pure mucinous carcinoma ${ }^{2}$.

We report a case of Mucinous Adenocarcinoma of gall bladder in a 60year-old female patient.

\section{CASE REPORT}

A 60-year-old female presented with pain in abdomen in right hypochondriac region since 3 days. On ultrasonography of abdomen, the patient was diagnosed as gangrenous cholecystitis with severe wall edema of gall bladder. Cholecystectomy was done and specimen of gall bladder was sent for histopathological examination.

\section{HISTOPATHOLOGICAL EXAMINATION}

Received a specimen of gall bladder which was grossly grey white, enlarged and showed extremely thickened wall measuring $1 \mathrm{~cm}$ in thickness. On cut section, the specimen revealed exophytic papillary tumour measuring $2.2 \times 1.6 \times 1.4 \mathrm{~cm}$ at the neck of the gall bladder (Fig 1). The rest of the GB mucosa was flattened.

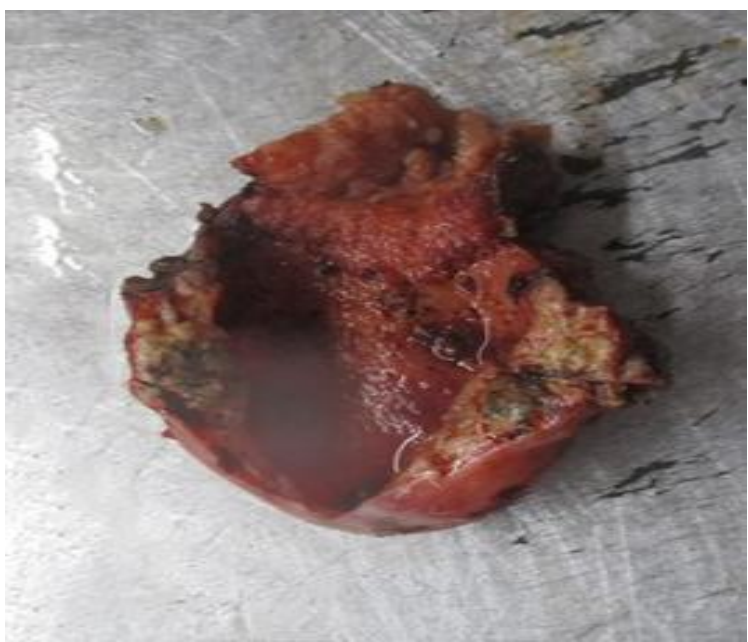

(Fig 1: Cut section shows exophytic papillary tumor) 
Microscopic examination revealed a tumour showing pools of extracellular mucin amidst with small clusters of tumour cells (Fig 2). The neoplastic cells were also arranged in small nests as well as few were scattered singly. The neoplastic cells showed enlarged vesicular atypical nuclei (Fig 3). Rest of the gall bladder showed extreme fibrosis, acute inflammation and areas of calcification. Immunohistochemistry profile of tumour revealed positivity for CK7, CA 19.9, MUC2 and CEA.

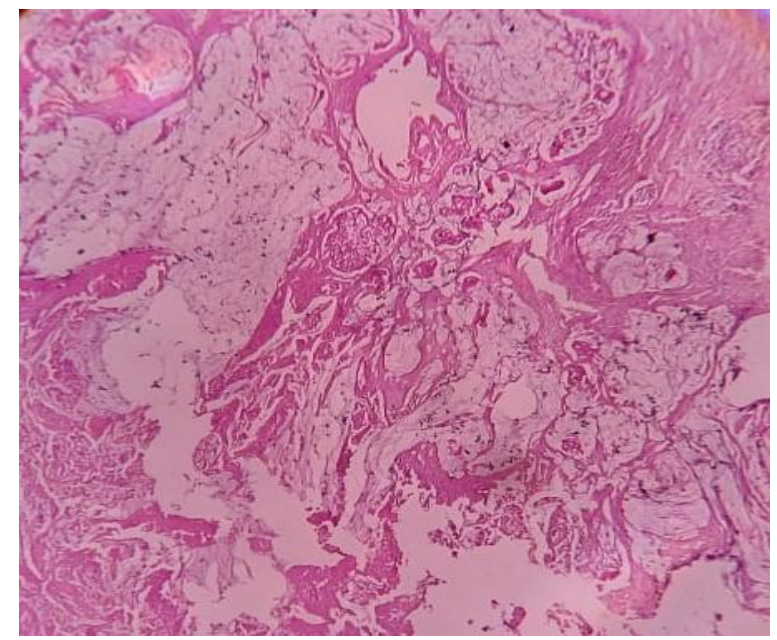

(Fig 2: Tumor showing pools of extracellular mucin with small cluster of tumor cells)

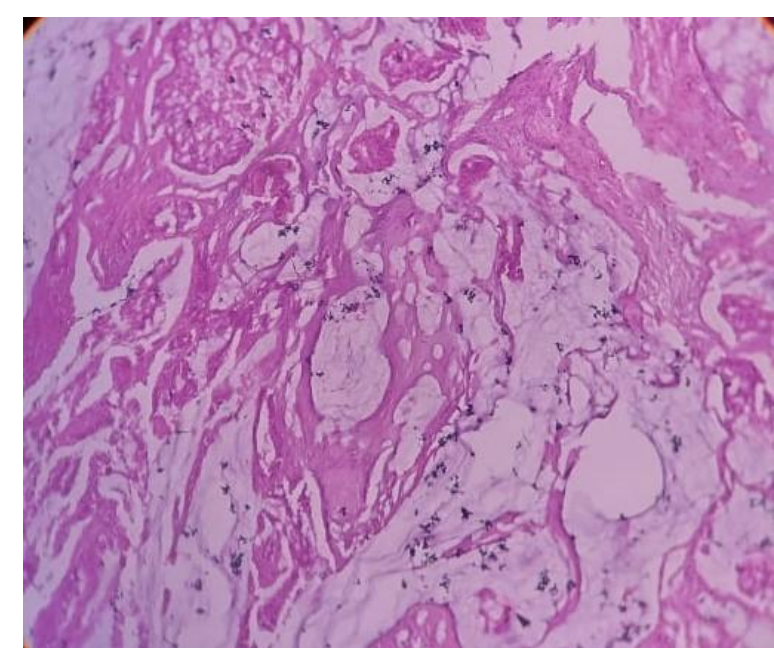

(Fig 3: The neoplastic cells showed enlarged vesicular atypical nuclei)

Considering these features, the diagnosis was given as moderately differentiated primary mucinous carcinoma of the gall bladder invading the muscle layer.

\section{DISCUSSION}

Gall bladder carcinoma is relatively uncommon malignancy. The risk factors for gall bladder carcinoma are gall stones, choledochal cyst, calcified porcelain gall bladder, sclerosing cholangitis and exposure to carcinogens ${ }^{3}$. In our case, the risk factor was porcelain gall bladder with cholecystitis. Most gall bladder carcinomas are conventional adenocarcinoma. Mucinous adenocarcinomas of gall bladder are rare and reveal more than $50 \%$ of mucin, a similar observation was there in our case. Adenocarcinoma with less than $50 \%$ extracellular mucin is regarded as adenocarcinoma with focal mucinous differentiation. Pure mucinous adenocarcinoma reveals more than $90 \%$ of extracellular mucin which is extremely rare in gall bladder ${ }^{4,5}$. Mucinous carcinomas of gall bladder reveal following characteristic features, they constitute $2.5 \%$ of gall bladder carcinomas. Although female predominance is seen in conventional gall bladder adenocarcinomas, it is not observed in mucinous adenocarcinoma. Most of these patients present with acute cholecystitis as seen in our case. These tumours frequently present at an advanced stage at the time of diagnosis as opposed to conventional adenocarcinomas of gall bladder and they reveal more aggressive behaviour ${ }^{6}$.

The differential diagnosis of mucinous carcinoma of gall bladder is conventional adenocarcinoma with focal mucinous differentiation, metastatic intestinal carcinoma and pancreatic mucinous carcinoma. In such background, immunohistochemistry study for CK $7 / 20$, CDX2, MUC2 is helpful 7 . Conventional gall bladder carcinomas are negative for MUC2 while mucinous adenocarcinoma shows MUC2 positivity. Pancreatic mucinous carcinoma is positive for CDX2. In our case, tumour was positive for CK7 and MUC2.

\section{CONCLUSION}

Mucinous adenocarcinoma is a rare variant of gall bladder carcinoma. It reveals 
aggressive behaviour with worst prognosis. It is necessary to differentiate this tumour from metastatic adenocarcinoma arising from other sites because of different treatment modality and different prognosis.

\section{Acknowledgement: None}

Conflict of Interest: None

\section{Source of Funding: None}

\section{Declaration of Patient Consent}

Appropriate patient consent was taken prior to publication in the journal.

\section{REFERENCES}

1. Albores - Saavedra J, Menck HR, Scoazec JC, Soehendra N, Wittekind C, Sriram PV, et al. Carcinoma of the gallbladder and extra hepatic bile ducts. In: Hamilton SR, Aaltonen LA, editors. WHO Classification of Tumors. Pathology and Genetics of Tumors of the Digestive System. Lyon: IARC Press, 2000; 206-12.

2. Gupte PA, Chaturvedi R, Patil LY, Joshi AS. Pure mucinous (colloid) adenocarcinoma of the gall bladder- A rare phenotype. Oncol. Gastroenterol. Hepatol. Reports, 2013; 2 (1): 27-29.

3. Dursun N, Escalona OT, Roa JC, Basturk O, Bagci P, et al. (2012 Mucinous carcinomas of the Gallbladder: clinicopathologic analysis of 15 cases identified in 606 carcinomas. Arch Pathol Lab Med 136: 1347-58.

4. Adsay VN, Klimstra DS (2009) Benign and Malignant Tumors of the Gallbladder and Extrahepatic Biliary Tract. In: Odze RD, Goldblum JR (eds.). Surgical pathology of the GI tract, liver, biliary tract, and pancreas. (2nd ed.) Saunders Elsevier, Philadelphia, pp.857-870.

5. Adsay VN (2010) Gallbladder, Extrahepatic Biliary Tree, and Ampulla. In: Mills SE, editor. Sternberg's Diagnostic Surgical Pathology. (5th ed) Lippincott Williams \& Wilkins. Philadelphia, pp: 1620-1624.

6. Zaydfudim V, Feurer ID, Wright JK, Pinson CW (2008) The impact of tumor extent (T stage) and lymph node involvement ( $\mathrm{N}$ stage) on survival after surgical resection for gallbladder adenocarcinoma. HPB (Oxford) 10: 420-427.

7. Giang TH, Ngoc TT, Hassell LA. Carcinoma involving the gallbladder: a retrospective review of 23 cases - pitfalls in diagnosis of gall bladder carcinoma. Diag Pathol. 2012;(10):2-8.

How to cite this article: Patil N, Nagar V. Mucinous carcinoma of gall bladder - a rare case report. Int J Health Sci Res. 2021; 11(6): 326-328. DOI: https://doi.org/10.52403/ijhsr. 20210648 